\title{
SEM Morphological Evaluation of the Effectiveness of Different Methods Used for Dentinary Cavitary Cleansing
}

\section{Clovis Pagani ${ }^{1}$, Flávia Goulart da Rosa Cardoso ${ }^{1,2}$, Eduardo Galera da Silva ${ }^{1}$, Carolina Baptista Miranda ${ }^{3, *}$, Sigmar de Mello Rode $^{1}$, and Tássia Monique dos Santos Pereira ${ }^{4}$}

${ }^{1}$ Department of Restorative Dentistry, Institute of Science and Technology, UNESP-Univ Estadual Paulista, São José dos Campos, SP, Brazil

${ }^{2}$ Department of Odontology, Endodontic Division, University of Taubaté-UNITAU, Taubaté, SP, Brazil

${ }^{3}$ Department of Restorative Dentistry, School of Dentistry, Federal University of Bahia, Salvador, BA, Brazil

${ }^{4}$ School of Dentistry, Federal University of Bahia, Salvador, BA, Brazil

\begin{abstract}
*Corresponding author: Carolina Baptista Miranda, Department of Restorative Dentistry, School of Dentistry, Federal University of Bahia, Salvador, BA, Brazil, Tel: (71) 999644400; E-mail: carolinabmiranda@terra.com.br
\end{abstract}

Received: 30 Jul, 2019 | Accepted: 22 Aug, 2019 | Published: 28 Aug, 2019

Citation: Pagani C, da Rosa Cardoso FG, da Silv EG, Miranda CB, de Mello Rode S, et al. (2019) SEM Morphological Evaluation of the Effectiveness of Different Methods Used for Dentinary Cavitary Cleansing. Int J Dent Oral Health 5(5): dx.doi.org/10.16966/2378-7090.301

Copyright: (c) 2019 Pagani C, et al. This is an open-access article distributed under the terms of the Creative Commons Attribution License, which permits unrestricted use, distribution, and reproduction in any medium, provided the original author and source are credited.

\section{Summary}

The purpose of this study was to evaluate the ultra-structural morphology of the dentin surface through Scanned Electron Microscopy (SEM) after the application of cavity cleaning products. Forty healthy human molar teeth were used, whose crowns were sectioned on the occlusal third for dentin exposure. The samples were embedded in chemically-activated acrylic resin, in a cast obtained from Polyvinyl Chloride (PVC) pipes. The surface treatment was carried out with a \#56 carbide bur coupled in high rotation, producing a residual coating called smear layer. The specimens were randomly divided into six groups according to dentin surface cleaning methods ( $n=6)$ : G1CO (control)-10s air spray application/30s washing with water jet /10s air spray application; G2AcF-phosphoric acid application at 37\%; G3CG-chlorhexidine gel application at 2\%; G4CL-chlorhexidine liquid application at 2\%; G5AcC-citric acid application at $20 \%$; G6HS-sodium hypochlorite application at $1 \%$. All specimens were fixed in chemical solution until SEM running. For SEM evaluation, the samples were dehydrated with ethanol, then gold-metalized and submitted to morphological analysis, less than 2000x magnification, evaluating the region's cleansing. A qualitative comparison of the smear layer removal was performed for all studies groups through image analysis. The applied substances were responsible for the total or partial smear layer removal, and the ones which removed most of the dentin mud layer were the phosphoric acid at $37 \%$, the liquid chlorhexidine at $2 \%$, the citric acid at $20 \%$, and the sodium hypochlorite at $1 \%$.

Keywords: Scanning Electron Microscopy; Dental cavity preparation; Acid etching; Dental Chlorhexidine

\section{Introduction}

Every time there is the need for a cavity preparation, whether when a tooth is affected with caries, or upon prosthetic preparation, residues are formed and they get deposited on cavity walls, originating the smear layer [1], a term introduced by Boyde A, et al. [2] from the Scanned Electron Microscopy (SEM) analyses. The dentin mud layer is composed of organic and inorganic components from the dental tissue, saliva, blood, and micro-organisms [3]. Furthermore, the smear layer may be containing mixture of bacteria and byproducts of them, and hence, it has been recommended to be removed [4] because it can affect the adaptation of sealing materials to the teeth walls [5].

According to Pashley DH [6], the dentin mud would be a natural cavity protector, which obliterate the dentin tubules and reduces the dentin permeability with more efficiency that any commercialized varnish. On the other hand, it could tamper with the adaptation or adhesion of dental materials onto the dentin and also serve as deposit of micro-organisms and its products, causing pulp injure [7].
Therefore, the cleansing of the dental cavity constitutes the final phase of the basic operational times series, in which residues that may harm the adaptation and the marginal sealing must be removed, apart from reducing micro-organisms and products that result from their metabolism. This action must not cause structural changes to the dentin tubules, so that the dentin permeability is not modified, and bacterial invasion remains difficult.

Still today, a great diversity of ideas and opinions exist regarding the indications of a chemical substance for the effective cleansing of cavities after cavity preparation. However, it is known that this procedure must be carried out with a material that is compatible with the biology of the dentin-pulp complex [8].

Several substances have been studies and indicated to promote the dentil tissue antisepsis [9-10], such as the phosphoric acid [11], the sodium hypochlorite [12]; the Ethylenediamine Tetraaceticacid (EDTA), 0,2-2,0\% chlorhexidine [13] and the aluminum oxide blast [14]. 
Chlorhexidine (CHX) is a widely known and a very popular antibacterial agent that decreases the level of cariogenic bacteria. CHX applied on the cavity surface of dentine may influence adhesive bond strength [13]. Sodium hypochlorite $(\mathrm{NaOCl})$ is widely used for antibacterial activity, lubrication, and removing organic remnants in smear layer during endodontic treatment [4]. Phosphoric acid and citric acid, as other organics acids, are believed to be used as smear removing agent [5].

These irrigation solutions which were used to clean the dental cavity and the adhesive system used for restoration affect the bond strength [14]. The irrigation solutions in contact with coronal dentin may alter the structure of the dentin and thus affect the sealing of posterior coronal restoration [15]. The combined used of these already recommended substances has also been evaluated. In the study of Ahir B, et al. [16], the efficiency of different irrigating solutions in the cleaning up and removal of smear layer from the apical third of root canals was compared using SEM:_sodium hypochlorite at $2.5 \%$ ( $\mathrm{NaOCl}), \mathrm{NaOCl}$ associated to EDTA at $17 \%, \mathrm{NaOCl}$ associated to citric acid at $10 \%$ and $\mathrm{NaOCl}$ associated to tetracycline hydrochloride at $1 \%$. The study concluded that the citric acid and the tetracycline hydrochloride irrigation agents associated to sodium hypochlorite may be used as an alternative to EDTA.

In this sense, there are innumerous chemical substances that may be applied by the dentist in the cavity cleaning processes for dentin mud removal, making the correct indication difficult. With the purpose to better clarify the clinical cavity cleansing protocols, the objective of this study was to comparatively analyze the ultra-structural morphology of the dentin surface using scanned electron microscopy (SEM) after the action of the different dentin cleaning methods upon final cavity preparation.

\section{Material and Methods}

This study was submitted and approved by the Committee of Ethics in Research (CEP/2.598.480) of the São José dos Campos School of Dentistry-UNESP.

\section{Specimens preparation}

Forty healthy human third molars extracted from patients aged 18-25 years due to orthodontic reasons were used. The patients were aware that its use would be for dental research purposes. The teeth were donated by clinics and private practices through the term of biological material donation. The teeth were cleaned and kept in saline solution to prevent them from dehydration until they were utilized.

The crowns were sectioned at their third occlusal portion with a diamond disc (Dremel, Breda, Holland) mounted in a rotary tool and under high speed rotation lathe (Nevoni, São Paulo, SP, Brazil), exposing dentin surface. Then, the dentin surface was polished with a 600-grit sandpaper (Fepa-P, Parambra, São Paulo, SP, Brazil), coupled to a circular polisher (DP-10, Parambra, São Paulo, SP, Brazil), under water cooling, aiming to standardize the superficial texture.

The specimens were embedded in a cylindrical shaped silicon cast with transparent chemically-activated acrylic resin (Jet-ClássicoSão Paulo, SP, Brazil). The radicular portion was embedded to the amelodentinal junction, leaving the coronal portion exposed.

After the final attaching to the acrylic resin, the resin blocks bases were polished with 400-grit sandpaper (Fepa-P, São Paulo, SP, Brazil) for flattening.

With a \#1094 diamond bur, the enamel was removed, and with a \#56 smooth cylindrical carbide (tungsten carbide) Round Cutting
Instrument (RCI), under rotation and cooling, the surface treatment was performed, producing a layer of dentin mud (smear layer). For each prepared specimen, a new RCI was used, assuring same preparation conditions to all samples. Aiming to standardize the pressure applied by the operator, a precision scale was used, on which his hand rested throughout the dental wear surface, with the attention to the same surface pressure application for all samples. After surface treatment, the specimens were kept in distilled water to prevent from dehydration, up to the moment of cavity cleansing.

\section{Experimental groups}

The specimens were randomly divided into six groups according to dentin surface cleaning methods (Table 1). After cavity cleansing, all specimens were abundantly washed with water for 30 seconds.

\section{Scanned Electron Microscopy}

After the application of the different cavity cleansing methods, the specimens were sectioned in the amelodentinal junction with the assistance of double-sided diamond discs (Microdont Micro Usinagem de Precisão Ltd., São Paulo, SP, Brazil), with care not to reach the region to be evaluated, with the purpose of serving as a guide for cleavage. Then, the specimens were externally washed and, with the assistance of a chisel, the teeth cleavage was performed in two halves, separating the coronal portion from the radicular portion, which was discarded. The coronal portion was fixed in a glutaraldehyde chemical solution until SEM evaluation moment. The samples were submitted to the laboratorial process of dehydration in concentrated ethanol solutions at $25 \%, 50 \%, 75 \%$ (20 minutes in each), $95 \%$ (30 $\mathrm{min}$ ) and in absolute ethanol (100\%) for one hour. Then, the specimens were placed on filter paper at room temperature until complete drying ( 24 hours).

After drying, the specimens were prepared for the scanning electron microscope (Scanning microscope-JSM-840A Jeol, Tokyo, Japan). For this, they were mounted on metallic stubs through a conducting carbon tape and silver glue, and the metallization was performed with a thin gold layer $(200 \AA)$ with a high pressure evaporator (DV-502-Denton $\mathrm{NJ})$. For each specimen, the electron microscope was positioned at an operational distance of approximately $25 \mathrm{~mm}$; an area of $200 \mu \mathrm{m} 2$ was irradiated with $15 \mathrm{~V}$ for $100 \mathrm{~s}$, with a $1 \mu \mathrm{m}$ electron beam penetration.

The cavity preparation cleaning confirmation was carried out by the verification of the presence or not of the smear layer observed in SEM. Representative areas were selected and photographed under 2000x magnification.

Two blind and independent examiners evaluated all images. The evaluation of images were made qualitatively with the attribution of scores, as described by Ahir B, et al. [16]: Score 1: No presence of smear layer-No detection of smear layer, clean and open dentin tubules; Score 2: Moderate presence of smear layer-No detection of smear layer; however, dentin tubules containing debris; Score 3: Accentuated presence of smear layer-With detection of smear layer, closed dentin tubules.

\section{Results}

The results found after the analysis of SEM obtained photomicrographs showed qualitative differences amongst the studied groups. Different smear layer treatment patterns were shown, according to the applied dentin cleaning product.

Most utilized products for the dentin cleansing showed score 1, with no presence of smear layer, with clean and open dentin tubules. These results were found for the Groups treated with Phosphoric 
Acid (G2AcF), liquid chlorhexidine at $2 \%(\mathrm{G} 4 \mathrm{CL})$, citric acid at $20 \%$ (G5AcC) and sodium hypochlorite at 1\% (G6HS) (Figures 1A-1D).

Only the group treated with chlorhexidine gel at $2 \%$ (G3CG) showed a pattern that was compatible to score 2 , that is, no detection of smear layer, however, dentin tubules containing debris (Figure 1E).

Lastly, with the control group, with which no dentin cavity cleansing substance was used, a dense smear layer was observed, with obstructed dentin tubules (score 3) (Figure 1F).

The photomicrographs showing the different patterns may be observed in figure 1 .

\section{Discussion}

The smear layer or dentin mud is an amorphous stratum constituted by organic and inorganic components that are formed upon cavity or endodontic preparation [17]. According to Luz MAAC, et al. [12] the smear layer treatment is of utmost importance for restoration performance. This fact was described by Nakabayashi when the author demonstrated that the hybrid layer formation occurred especially through the penetration of adhesive systems in the dentin, being the mechanical adhesion even more important that the chemical bonding [18]. On the other hand, Nakabayashi N [19] described that the care with the smear layer treatment is important, as the dentin's excessive demineralization promotes collagen denaturing, apart from the fact that the adhesives do not manage to penetrate with the same depth the acid conditioning manages to.

In the present study, a tip under high rotation was used for dentin mud formation on the dental surface, a method that was also used by Luz MAAC, et al. [12] and Götze Gda R, et al. [20]. This procedure was efficient for this purpose, as in the control group, cut with the diamond tip and only treated with water/air spray, the formation of the dentin mud layer over the surface was observed, according to the exposed in the photomicrograph. In this group, dental surface irregularities were identified, originated by the diamond tip used for wear, a fact that was also described by Luz MAAC, et al. [12].

Regarding the other groups, with which cavity cleansing agents were used, it was observed that all applied agents produced some sort of dentin mud removal. Within the samples treated with phosphoric acid, liquid chlorhexidine at $2 \%$, citric acid at $20 \%$, and sodium hypochlorite at $1 \%$, the dentin surface presented absence of smear layer and open dentin tubules. Within the samples treated with chlorhexidine gel at $2 \%$, the removal of smear layer also occurred, however, with some maintenance of debris areas over the dentin tubules.

Amongst the cavity cleansing tested products, the application of phosphoric acid is the most established according to literature, acting as an efficient cavity cleansing agent and being responsible for the complete removal of dentin mud and for the opening of dentin tubules, as acknowledged in this research upon its use in a concentration of $37 \%$. Such results were also found in other studies, like the one of Goes MF, et al. [21] who used the phosphoric acid at $35 \%$ and $10 \%$, and who also registered dentin mud removal and tubules opening. Likewise, Luz MAAC, et al. [12] described complete smear layer removal with the application of phosphoric acid, and also informed that this acid promoted effects both on the dentin structure and its permeability.

Another product that has been much utilized as a cavity cleansing agent is the chlorhexidine. According to Breschi L, et al. [22] its use has been much disseminated, once it has an inhibiting action onto dentin's metalloproteinase, fact that, according to Komori PCP, et al. [23] favors resin composite restorations durability. It was observed that

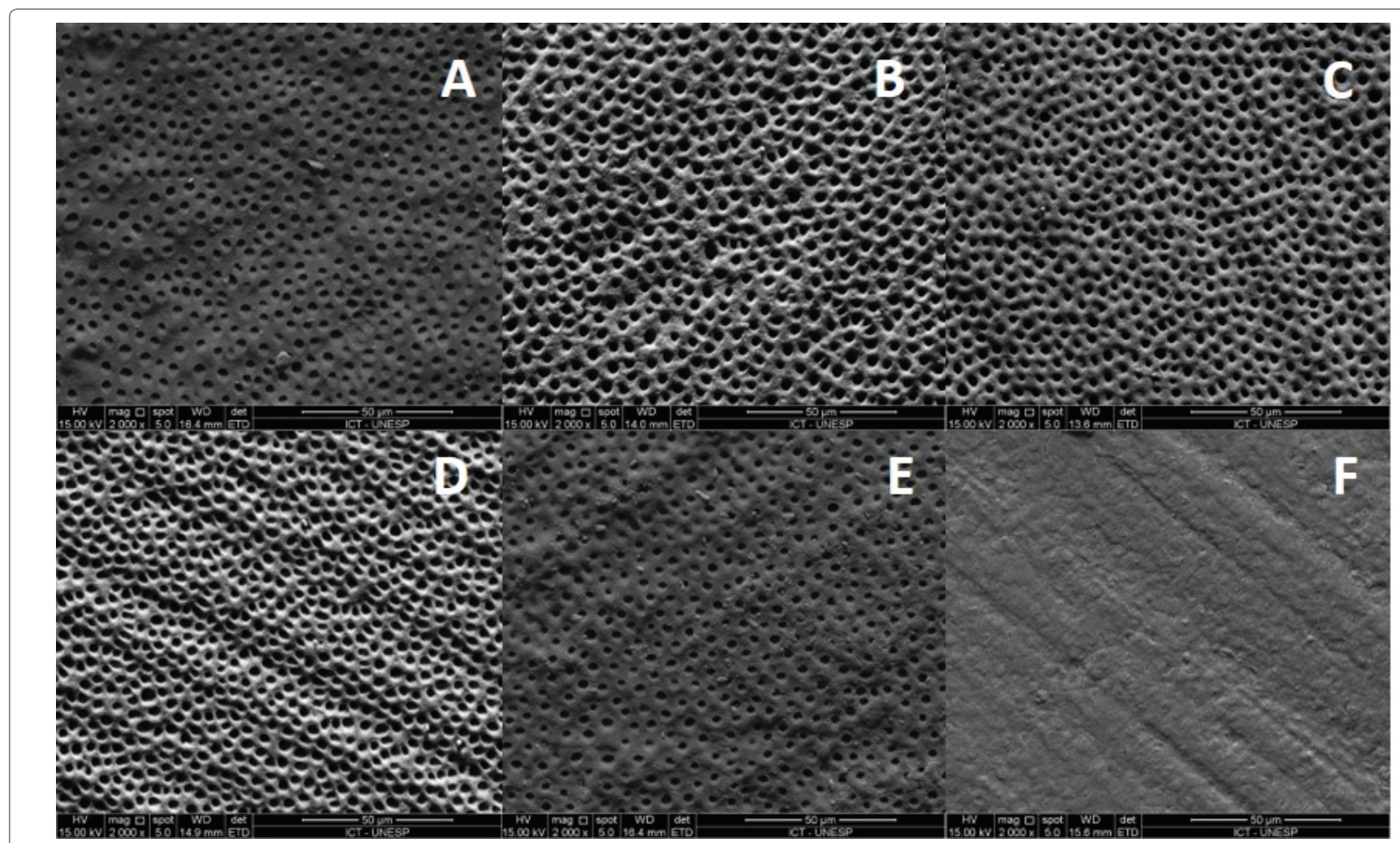

Figure 1: SEM morphological evaluation of the effectiveness of different methods used for dentinary cavitary cleansing (2000x magnification). A) Group 1AcF; B) Group 4CL; C) Group 5AcC; D) Group 6HS; E) Group 3CG; F) Group 1CO. 
Table 1: Experimental Groups distribution.

\begin{tabular}{|c|c|c|}
\hline Groups & Cavity Cleansing & Application Mode \\
\hline \multirow{3}{*}{ G1CO (n=4) } & \multirow{3}{*}{ Water/Air Spray (Control) } & 10s drying with air jets \\
\hline & & 30 s washing with water jets \\
\hline & & 10s drying with air jets \\
\hline \multirow{4}{*}{ G2AcF $(n=6)$} & \multirow{4}{*}{ Phosphoric acid 37\% (Ultra-Etch, Ultra dent Products Inc., Utah, USA) } & 10s drying with air jets \\
\hline & & 30s acid application \\
\hline & & 30 s washing with water jets \\
\hline & & 10s drying with air jets \\
\hline \multirow{4}{*}{ G3CG $(n=6)$} & \multirow{4}{*}{ Chlorhexidine gel $2 \%$ (Consepsis V- Ultradent Products Inc., Utah, USA) } & 10s drying with air jets \\
\hline & & 60 s brushing in the CLX with a micro brush \\
\hline & & 30s washing with water jets \\
\hline & & 10s drying with air jets \\
\hline \multirow{4}{*}{ G4CL $(n=6)$} & \multirow{4}{*}{$\begin{array}{l}\text { Liquid Chlorhexidine 2\% (Concepsis-Ultradent Products Inc., Utah, } \\
\text { USA) }\end{array}$} & 10s drying with air jets \\
\hline & & 60 s brushing in the CLX with a micro brush \\
\hline & & 30s washing with water jets \\
\hline & & 10s drying with air jets \\
\hline \multirow{4}{*}{ G5AcC $(n=6)$} & \multirow{4}{*}{ Citric acid $20 \%$ (Citric acid-Ultradent Products Inc., Utah, USA) } & 10s drying with air jets \\
\hline & & 60 s brushing in the substance with a micro brush \\
\hline & & 30s washing with water jets \\
\hline & & 10 s drying with air jets \\
\hline \multirow{4}{*}{ G6HS $(n=6)$} & \multirow{4}{*}{$\begin{array}{l}\text { Sodiumhypochlorite 1\% (Asfer Ind. Químicas Ltd.-São Caetano do Sul, } \\
\text { Brazil) }\end{array}$} & 10s drying with air jets \\
\hline & & 60 s brushing in the substance with a micro brush \\
\hline & & 30s washing with water jets \\
\hline & & 10s drying with air jets \\
\hline
\end{tabular}

when the chlorhexidine was used in its liquid form, the smear layer removal was complete, with dentin tubules exposure; however, when used in its gel form, debris were found in the tubules, possibly due to greater difficulty of the gel in removing the dentin mud, considering the applied concentration was the same. Neri JR, et al. [24] also used the chlorhexidine gel at $2 \%$ and observed that it was not efficient in the smear layer removal from the dentin surface.

Regarding the use of citric acid, Götze Gda R, et al. [20] described its effects on the dentin mud of deciduous teeth. In this case, the authors applied different concentrations of citric acid $(4 \%, 6 \%, 8 \%$, and $10 \%)$, associated to sodium hypochlorite at $1 \%$. They observed that under all concentrations, there was complete dentin mud removal, corroborating with the present study. However, the authors concluded that the citric acid at $8 \%$ and $10 \%$ promote the enlargement of dentin tubules, suggesting damages to the peritubular dentin. It is important to highlight that the study of Götze Gda R, et al. [20] used the sodium hypochlorite at $1 \%$ before applying the citric acid, and this fact was probably responsible for the dentin tubules opening, whereas in this study, the sodium hypochlorite at $1 \%$ alone was responsible for the dentin mud removal and for the opening of the tubules. In another group of samples from this study (group 5), the citric acid was applied in isolation. Despite being used in a larger concentration, considering the citric acid was applied at $20 \%$, no damages were observed. Likewise, Reis C, et al. [25] evaluated the effects of the citric acid at $1 \%, 5 \%$, and $10 \%$ on the smear layer, using different application timing $(15 \mathrm{~s}, 30 \mathrm{~s}, 60 \mathrm{~s}, 180 \mathrm{~s}$, and 300s). Results showed that the citric acid action occurred 15s from application and after $60 \mathrm{~s}$ of irrigation, peritubular erosions were observed. The dentin mud removal results were equivalent to the ones observed in this current study, although the applied concentration was higher $(20 \%)$. It is believed that it occurred for to the time of application being shorter (10s), matching concentration $v s$ exposure period.

The applied substances were responsible for the total or partial smear layer removal, and the ones which removed most of the dentin mud layer were the phosphoric acid at $37 \%$, the liquid chlorhexidine at $2 \%$, the citric acid at $20 \%$, and the sodium hypochlorite at $1 \%$.

\section{Competing Interests}

The authors deny any conflicts of interest related to this study.

\section{Ethical Approval}

This study was previously approved by the Research and Ethics Committee of UNESP-São Paulo State University, São José dos Campos, Brazil (CEP/2.598.480).

\section{References}

1. Paterson RC, Watts A (1990) Dentine smear layer and bonding agents. Review: 1 . Smear layer-nature of the smear layer. Restorative Dent 6: 19-21.

2. Boyde A, Switsur VR, Stewart ADG (1963) Advances in fluorine research and dental caries prevention. Oxford Pergamon Press, UAS 185-193. 
3. Shulein TM (1988) The smear layer on dentin. A status report for the American Journal of Dentistry. Am J Dent 1: 264-270.

4. Arslan S, Balkaya H, Çakir NN (2019) Efficacy of different endodontic irrigation protocols on shear bond strength to coronal dentin. J Conserv Dent 22: 223-227.

5. Mohammadi Z, Shalavi S, Yaripour S, Kinoshita JI, Manabe A, et al. (2019) Smear Layer Removing Ability of Root Canal Irrigation Solutions: A Review. J Contemp Dent Pract 20: 395-402.

6. Pashley DH (1984) Smear layer: physiological considerations. Oper Dent Suppl 3: 13-29.

7. Ladalardo WD, Penna LAP, Rode SM (2005) A influência da camada de smear na adaptação de retentores protéticos. Cienc Odontol Bras 8: $15-22$.

8. Sarac D, Bulucu B, Sarac YS, Kulunk S (2008) The effect of dentincleaning agents on resin cement Bond strength to dentin. J Am Dent Assoc 139: 751-758.

9. Rosin C, Arana-Chavez VE, Netto NG, Luz MA (2005) Effects of cleaning agents on Bond strength to dentin. Braz Oral Res 19: 127133

10. Zortuk M, Gumus HO, Kilinc HI, Tuncdemir AR (2012) Effect of different provisional cement remnant cleaning procedures including Er:YAG laser on shear Bond strength of ceramics. J Adv Prosthodont 4: 192-196.

11. Kanca J, Gwinnett AJ (1994) Successful Marginal Adaptation of a Dentin-Enamel Bonding System In vitro and In vivo. J Esthet Dent 6: 286-294.

12. Luz MAAC, Garone Netto N, Arana-Chavez VE, Sobral MAP, Singer JM (2000) Evaluation of chemical and/or mechanical treatments of the smear layer as revealed by scanning electron microscopy-a blind comparative study. Pesq Odont Bras 14: 101-106.

13. Lapinska B, Klimek L, Sokolowski J, Lukomska-Szymanska M (2018) Dentine Surface Morphology after Chlorhexidine Application-SEM Study. Polymers (Basel) 10: E905.

14. Coli P, Alaeddin S, Wennerberg A, Karlsson S (1999) In vitro dentin pretreatment: Surface roughness and adhesive shear bond strength. Eur J Oral Sci 107: 400-413.
15. Farina AP, Cecchin D, Barbizam JV, Carlini-Júnior B (2011) Influence of endodontic irrigants on bond strength of a self-etching adhesive. Aust Endod J 37: 26-30.

16. Ahir B, Parekh V, Katyayan MK, Katyayan PA (2014) Smear layer removal efficacy of different irrigating solutions: a comparative scanning electron microscope evaluation. Indian J Dent Res 25: 617622.

17. McComb D, Smith D (1975) A preliminary scanning electron microscopic study of root canals after endodontic procedures. J Endod 1: 238-242.

18. Nakabayashi N (1985) Bonding of restorative materials to dentine: the present status in Japan. Int Dent J 35: 145-154.

19. Neter J, Wasserman W, Kutner MH (1990) Applied Linear Statistical Models: Regression, Analysis of Variance, and Experimental Designs. ( $3^{\text {rd }}$ edtn) Irwin, 1127p.

20. Götze Gda R, Cunha CB, Primo LS, Maia LC (2005) Effect of the sodium hypochlorite and citric acid association on smear layer removal of primary molars. Braz Oral Res 19: 261-266.

21. Goes MF, Sinhoreti MA, Consani S, Silva MA (1998) Morphological effect of the type, concentration and etching time of acid solutions on enamel and dentin surfaces. Braz Dent J 9: 3-10.

22. Breschi L, Mazzoni A, Nato F, Carrilho M, Visintini E, et al. (2010) Chlorhexidine stabilizes the adhesive interface: a 2-year in vitro study. Dent Mater 26: 320-325.

23. Komori PCP, Pashley DH, Tjaderhane L, Breschi L, Mazzoni A, et al. (2009) Effect of $2 \%$ Chlorexidine Digluconate on the Bond Strenght to normal versus caries-affected dentin. Oper Dent 34: 157-165.

24. Neri JR, Passos VF, Viana FBA, Rodrigues LKA, Saboia VPA, et al. (2011) Efficacy of smear layer removal by cavity cleaning solutions: an atomic force microscopy study. Rev Odontol Cienc 26: 253-257.

25. Reis C, De-Deus G, Leal F, Azevedo E, Coutinho-Filho T, et al. (2008) Strong effect on dentin after the use of high concentrations of citric acid: an assessment with co-site optical microscopy and ESEM. Dental Mater 24: 1608-1615. 